\title{
CANCER VACCINES WITH EMPHASIS ON A VIRAL ONCOLYSATE MELANOMA VACCINE*
}

\author{
J. C. HORVATH, ANDREA HoRAK, J. G. SinKOVICS, MARY PRITCHARD, \\ StaCia PENDLETon, and Elizabeth HORVATH
}

St. Joseph's Hospital Cancer Institute, Department of Medical Microbiology and Immunology
and Department of Medicine, University of South Florida College of Medicine, Tampa, Florida, USA

(Received November 12, 1998)

(Accepted December 9, 1998)

\begin{abstract}
Biotherapy of malignant diseases has become the fourth treatment modality besides surgery, chemo- and radiotherapy. Whole cell melanoma vaccines with or without BCG and other adjuvants, purified ganglioside and shed antigens, recombinant viruses carrying tumor antigens, dendritic cells pulsed with antigenic peptides etc. are in clinical trials.

Efficacious viral oncolysate vaccines induce the host to mount tumor-specific cytotoxic T-cell response and prevention of relapses is supported by clinical trials. The use of "polyvalent" whole cell vaccines vs. purified or genetically engineered single antigen vaccines is justified as $i$. only very few single tumor antigens are present in all tumors of a given histological type; and ii. antigen modulation occurs in tumors rendering them resistant to immune attack generated by vaccine against a single antigen. Thus polyvalent vaccines immunize against several antigens vs. against a selected antigen.
\end{abstract}

"Part of this paper was presented at the scientific meeting on May 22, 1997 at Semmelweis University Medical School in honor of professors Ilona Szeri and István Nász 70th birthday. Invited paper to commemorate the 50th anniversary of the Department of Microbiology Semmelweis University Medical School.

Joseph C. Horvath, ANDREa Horak, Mary Pritchard, Stacia Pendleton, JosePh G. Sinkovics

St. Joseph's Hospital Cancer Institute

3001 W Martin Luther King Blvd., Tampa, FL 33607, USA

ElizaBeth HoRVATH, JoSEPH C. HORVATH, JosePH G. SinKovics

Department of Medical Microbiology and Immunology, University of South Florida College of Medicine Tampa, Florida, USA 


\section{Introduction}

The occasional observations of the often short-lived spontaneous remissions with inflammatory infiltration in melanomas and renal cell carcinomas since long time have suggested the existence of tumor-specific antigens and the presence of tumor-specific immunity and recognized the pivotal role of the immune system in the control of malignant tumors.

In their native forms naturally occurring tumors seldom generate strong, rejection type tumor-specific immunity. Our perception of the interaction between the immune system and the tumor has gone through significant changes during the last decades. We envisioned the role of the host defense as immune surveillance, continuously seeking and destroying emerging malignant cells and protecting against developing tumors. We know by now that the encounter between the immune system and the weakly antigenic tumor cells does not necessarily result in protective immunity; it might generate immunological tolerance or even "tumor enhancement" as well. The outcome of the encounter depends on the way the antigen is presented to the immune system. Even the presence of strong delayed type hypersensitivity reaction can be associated with failure to control tumor growth due to adverse circumstances, as low level of expression of MHC antigens or immune modulation in the target cells, production of immunosuppressive substances by the tumor, etc. $[1,2]$.

The anergy or tolerance toward week tumor antigens can be overcome if such antigens are presented in an "unnatural way" to the immune system. The immune response generated by the vaccine depends on the adjuvant used as well. While alum widely used adjuvant in classical vaccines against microbial infections - promotes the generation of humoral immune response, BCG applied with or scarified over the site of the anti-cancer vaccination generates cellular immunity considered to be of primary importance for efficient anti-tumor immunity. DETOX (detoxified endotoxin of Salmonella minnesota and cell wall skeleton of Mycobacterium phlei, squalane and emulsifier) is used in Mitchell's Theraccine [3]. The use of interferons (IFN), G-CSF/GMCSF and IL-2 as adjuvants to vaccine is gaining significance [4, 5]; maybe IL-12 will be used in the future.

\section{SYNOPSIS OF TUMOR IMMUNOLOGY}

\section{Tumor antigens}

Tumor specific and tumor associated antigens of malignant melanoma are among the most studied ones in human tumor immunology. The first melanoma antigens were recognized by use of patients' sera. The recent wave of new melanoma associated antigens was discovered using tumor-specific $\mathrm{CD}^{+} \mathrm{T}$-cell clones and peptides eluted from the MHC complex of the tumor cells [6-8].

Tumor specific antigens are seldom present in normal or embryonic tissues and generally are products of genetic mutations (chromosomal translocation, point mutations 
etc.) such as the abl-bcr fusion protein in Philadelphia chromosome ${ }^{+}$chronic myelogenous leukemias or they are expressed from the genomes of transforming viruses (E6 and E7 in human papillomavirus-transformed cervical cancer, LMP of EBV in AIDS associated non-Hodgkin lymphomas as well as in endemic Burkitt's lymphoma). Tumor-specific antigens can be generated by irregularly spliced transcription of tissue specific antigens such as the tyrosinase-related protein, which is recognized by CTL [9]. Mutated p53 is also antigenically different from wild type p53. Tumor-specific antigens are good candidates to be used as cancer vaccines [10]. Shared tumor antigens are specific to the same type of tumor and are not or weakly expressed in normal tissues. The MAGE family of antigens are expressed in the majority of melanomas and only weakly in the testis [11, 12]. These antigens are good candidates for tumor-specific vaccine development.

Tumor-specific differentiation antigens are non-mutated proteins expressed in the tumor and in normal tissue from which the tumor originated. Tyrosinase, MART-1/melanA and gp100 melanoma antigens are non-mutated proteins expressed in melanocytes as well but still generate $\mathrm{T}$-cell response in patients with melanoma.

\section{Antigen presentation}

Cytotoxic lymphocytes identify protein antigens with low efficiency but recognize antigenic peptides, processed by antigen presenting cells (APC) and presented at the groove of the MHC, with high efficiency. Professional APC (dendritic cells, macrophages, etc.) express accessory co-stimulatory molecules such as HLA B7.1 and B7.2 which link to specific receptor CD28 on the lymphocyte surface. Such event happens as an introduction to antigen presentation (1st signal). This is followed by the lower affinity TCR-antigen binding to antigenic peptide in the MHC pocket (2nd signal) and results in "capping" of TCR and concludes finally in stimulation and proliferation of the antigen-specific T-cell clone. Antigens presented by non-professional APC such as tumor cells without co-stimulatory molecules result in apoptotic death of involved lymphocytes and tolerance will develop [13]. However, when CD70 (CD27L) and/or CD40L (CD154, expressed on $\mathrm{T}$ cell membrane and essential for dendritic cell activation as well as for $\mathrm{T}$ and B-cell help) are transduced into murine tumor cell lines the transplanted tumor cells generate protective anti-tumor immune response [14].

A frequent finding is that HLA antigens in human tumors are expressed weakly or not at all [15-21]. Sometimes the loss of HLA expression is a consequence of chromosome rearrangements and involves peptide transporter molecules TAP1 and TAP2, transporting peptides from the cytosol to the endoplasmic reticulum [22]. These melanoma cells require IFN induction of TAP1 and -2 as well as transduced HLA-A2 to replace the rearranged allele to be targets to CTL. When such tumor cells act as APC they cause tolerance and themselves are poor targets for cytotoxic T lymphocyte attack as well. Melanoma cells freshly extracted from a metastatic lesion of one of our patient expressed MHC Class I antigens (tested with antibodies specific to its $\beta$ chain known also as $\beta$-2microglobulin). During immunization with an unmodified whole cell autologous 
melanoma vaccine relapse occurred: tumor cells from that new metastatic lesion ceased expressing $\beta$-2-microglobulin (Figure 1). These cells were poor targets for and escaped to be killed by cytotoxic T-cells generated by the vaccine.

Fig. 1. Flow cytometry analysis of melanoma cells obtained from metastatic lesions from a patient before (A) and after (B) active immunization with an autologous unmodified melanoma vaccine. The cells were stained with FITC labeled human $\beta$-2-microglobulin specific mouse monoclonal antibody

Dendritic cells (DC) are the most potent APC. They present antigenic peptides to T-lymphocytes through Class I and Class II HLA molecules (for $\mathrm{CD}^{+}$and $\mathrm{CD} 4^{+}$ lymphocytes, respectively). The source of DC determines which kind of cytokines they produce and whether Th1 or Th2 type response is generated (regulated by IL-12). Activated DC of systemic origin (spleen, etc.) induce IFN $\gamma$ and IL-2 production and TH1 type (cell mediated, delayed type) response in T-lymphocytes whereas DC from Peyer's patches (mucosal DC) promote IL-4 and IL-6 production and Th2 (predominantly humoral) immune response [23]. As DC can be cultured, in vitro from peripheral blood and can be pulsed (empty MHC grooves dressed in vitro) by antigenic peptides or tumor cell lysates their significance as components of cancer vaccines is increasingly recognized (vide infra).

\section{CANCER VACCINES}

Crude whole cell or cell lysate vaccines

Whole cell based vaccines contain large amount of normal cell components, however, they also represent a wide range of tumor-specific antigens. Early passage autologous tumor cell vaccines carry all tumor antigens expressed in the patient's resected 
tumor but immune modulation or mutation in a metastasis developing later can render it resistant to immune attack generated by the vaccination. The use of allogeneic vaccines is justified by the existence of common (shared) tumor-specific antigens; to cover as many existing antigens specific to the particular tumor type as possible, however, such vaccines contain a mixture of several different tumor cell lines or lysates (from 2 lines in Mitchell's cell lysate vaccine to 8 cell lines in Cassel's viral oncolysate). Mitchell's allogeneic melanoma cell lysate vaccine induced objective responses (average duration 21 months, one lasted over 6 years) in a therapeutic setting in $25 / 106$ patients with metastatic disease, including choroidal melanoma [24-26]. Patients suffering from stage IV metastatic melanoma with measurable disease responded better to chemotherapy than to Mitchell's vaccine in a therapeutic setting (12.3 months OS, 2CR, 5PR, 19 SD vs. 9.4 months OS, $2 \mathrm{CR}, 3 \mathrm{PR}$ and $5 \mathrm{SD}$, respectively) but the quality of life was better and there were no toxic side effects in the vaccinated group. The patients who failed on the Theraccine vaccine responded better to IFN- $\alpha$ treatment than non-vaccinated patients [27]. Expanding clones of tumor-protecting suppressor cells can be eliminated by low dose cyclophosphamide [28]. Morton's polyvalent whole cell allogeneic vaccine is admixed with BCG and the patient is premedicated with cimetidin, indomethacin and/or cyclophosphamide, to block histamine receptor ${ }^{+}$suppressor T-cells and prostaglandins [29]. This vaccine induced regressions in $23 \%$ of patients with measurable disease and increased the median survival as well as the 5 years survival of patients suffering from stage III disease with $20 \%$ and is claimed to have reduced the incidence of brain metastases when used in adjuvant setting.

To increase immunogenicity the tumor cells are xenogenized with dinitrophenol (DNP) in Berd's autologous vaccine [30] or are infected with oncolytic viruses (vide infra). Autologous melanoma vaccine xenogenized by DNF induced delayed type hypersensitivity (DTH) reactions in vaccinated patients. The 5 year survival of patients with positive DTH to untreated melanoma cell antigens was $71 \%$ compared to $49 \%$ of patients with negative DTH [31]. The DNP-modified vaccine induces clonal expansion of CTL with TCR-Vß14 in existing metastases, capable of lysing melanoma cells [33]. Preliminary results with DNP-modified autologous ovarian carcinoma vaccine are also promising.

\section{Anti-idiotype monoclonal antibodies as cancer vaccines}

Anti-idiotype antibodies bearing the internal image of a tumor associated antigen offer unique opportunity as cancer vaccines. Active tumor-specific immunotherapy with the mouse monoclonal antibody MK2-23 bearing the image of high molecular weight melanoma associated antigen promotes longer survival of vaccinated patients [33].

Cellular vaccines genetically engineered to express tumor antigens, lymphokines or transplantation antigens

Preclinical studies with murine transplantable tumors demonstrated that the immunogenicity of weakly antigenic tumor cells can be efficiently increased if tumor cells, after transduction with retroviral vectors encoding cytokine genes, secrete functionally active cytokines. Tumor cells double-transduced with IL-7 and HSV 
thymidine kinase (TK) cause augmentation of cytotoxic T-cell production and downregulation of immunosuppressive TGF $\beta$; TK provides the way of eliminating the injected vaccine cells with gancyclovir treatment [34]. Local production of lymphokines potentiates APC function (IFN, GM-CSF) and activates lymphocytes (IL-2) without the side effects of systemic lymphokine therapy. Human clinical trials are in progress using cytokine gene-transduced autologous kidney cancer or melanoma cells as vaccines [3537]. IL-4 transduced dermal fibroblasts coinjected with irradiated tumor cells are in a phase I/II clinical trial [38]. Tumor-antigen transfected DC (with or without cotransfected cytokine genes) joined the rank $[39,40]$. These settings work well in preclinical trials and generate clinical responses in patients with advanced disease. Several clinical trials are in progress to demonstrate their usefulness in generating long-term tumor-specific protective immunity.

\section{Partially purified tumor antigens}

Bystryn's melanoma vaccine consists of antigens shed by 3 human and 1 hamster melanoma cell lines. The disease free interval (DFI) of patients with stage III melanoma who developed high anti-melanoma antibody titer to vaccination with shed melanoma antigens was $52 \%$ and OS was $71 \%$ vs. $31 \%$ and $44 \%$ among patients with no antibody response to the vaccine [41]. Several melanoma-specific proteins, identified using sera of vaccinated patients, represent candidate antigens for potential new vaccines [42].

\section{Ganglioside tumor antigens}

Gangliosides are continuously shed from tumor cell membranes and are immunosuppressive: binding to IL-2R they interfere with IL-2 binding and inhibit T-cell activation [43]. The role of a ganglioside based vaccine is to raise antibodies capable of removing and neutralizing circulating gangliosides shed by tumor cells. High titer of antibody response to GM2 ganglioside antigens conjugated to keyhole limpet hemocyanin (KLH) correlated with longer disease free and overall survival [44-46]. A multicenter randomized trial is ongoing to compare the effectiveness of a KLH-conjugated GM2 vaccine with high dose IFN $\propto$ in patients with deep stage II and stage III melanoma.

\section{Tumor-antigen derived T-cell specific peptides}

Since technology became available to identify tumor-specific antigenic peptides, presented in the groove of MHC molecules and capable to induce cytotoxic T-cell response, several approaches evolved to use peptides as tumor vaccines. Patients with evidence of metastatic melanoma received MART-1 and gp100 specific synthetic peptides (modified to increase binding to MHC molecule) admixed with incomplete Freund adjuvant. When the vaccine was administered with a single cycle of high dose IL-2 13 (42\%) out of 31 patients experienced clinical response after at least 2 vaccine cycles [47]. 
Dendritic cells (native or engineered to express cytokines), pulsed with tumor cell lysates or peptides or fused with tumor cells

Use of the non-professional antigen presenting tumor cells fused to bone marrow derived dendritic cells offers a unique opportunity for tumor vaccine. Fusion of murine MC38 adenocarcinoma to dendritic cells renders the new entity non-tumorigenic and morphologically dendritic cell-like. Vaccination of mice with the fused cells provided $100 \%$ protection against tumor cell challenge by generating cytotoxic T-cells able to lyse tumor cells [48]. In 9 out of 10 animals with established tumors the generated CTL could eliminate metastatic disease as well. These very impressive results are yet to be confirmed in human clinical trials.

Tumor lysates (without any further preparation of tumor-specific antigens) pulsed onto dendritic cells increased cure rate and survival from the parent transplantable tumors [49]. A European study using such approach documented strong clinical response to a therapeutic vaccine consisting of cultured dendritic cells pulsed with melanoma cell lysates or tumor-specific peptides, recognized by T-cells [50]. The vaccine generated delayed type hypersensitivity reaction (DTH) and objective responses were observed in 5 out of 15 patients with advanced melanoma (2CR, 3 PR).

\section{Recombinant viruses encoding specific tumor antigens}

The first reports about the use of recombinant viruses encoding tumor-specific antigens for cancer vaccine, which generate DTH and tumor-protection in preclinical studies appeared in the late $80 \mathrm{~s}$. Such antigens included retrovirus env genes, EBV latent membrane protein, polyoma virus $\mathrm{T}$ antigens and melanoma specific g97 protein in vaccinia virus [51-54]. Poliovirus vectors joined the rank as they proved to be able to elicit cytotoxic $\mathrm{T}$ cell mediated tumor-specific immune response in mice (55). Canarypox virus vectors encoding mutant or wild type p53 were found to be equally efficient in protecting mice against the challenge with highly tumorigenic fibroblast tumor cell line expressing mutated p53 [56]. However, tumor cells down-regulating p53 expression escaped the immunologic rejection. Immunization with a recombinant vaccinia virus encoding human prostate specific acid phosphatase generates CTL responses in rats: can cross-species immunization cure prostate cancer or prevent relapse [57]? E6 and E7 proteins from human papillomavirus type 16 and 18 in a live recombinant vaccinia virus induced virus specific antibodies in patients with late stage cervical cancer in a Phase I/II trial suggesting a feasible way to fight this virus-induced tumor [58-60]. A vaccinia virus vector encoding the human prostate specific antigen (PSA) generated cytotoxic lymphocyte response in rhesus monkey (94\% amino acid homology between the rhesus and human PSA); human clinical trials will certainly follow [61].

Viral vectors themselves generate immune response that can limit their repeated use. When different viral or plasmid vectors are used for priming and boosting with tumor antigens the anti-tumor immune response exceeds the one obtained with a single vector system [62]. 


\section{DNA vaccines}

DNA vaccines utilize plasmid or viral DNA constructs containing a potent eukaryotic promoter and a gene encoding a tumor antigen or costimulatory molecule. Such a construct encoding a tumor antigen may be directly injected to muscle cells rendering them to produce the corresponding antigen protein and generating humoral and cellular anti-tumor immune response [for a review, 63]. Gold particle bound plasmid constructs can be introduced to skin by "gene gun" technology [reviewed in 64]. When Allovectin-7, the HLA-B7 allogeneic class I MHC encoding plasmid, formulated with cationic lipid was injected into metastatic melanoma lesions with CT guidance, CTL response was generated and out of 10 injected patients 6 showed clinical response ( 1 durable complete response). Bystander effect was also observed, i.e. lesions not injected also diminished in size $[65,66]$.

Table I

Chemo-immunotherapy of patients with metastatic sarcomas (Oct'76 - Feb '77)

\begin{tabular}{lccccc}
\hline Treatment & $\begin{array}{c}\text { No. of } \\
\text { patients }\end{array}$ & $\begin{array}{c}\text { Complete } \\
\text { remission }\end{array}$ & $\begin{array}{c}\text { Partial remission } \\
\text { and stable disease }\end{array}$ & $\begin{array}{c}\text { Progressive } \\
\text { disease (death) }\end{array}$ & $\begin{array}{c}\% \text { of } \\
\text { progressors }\end{array}$ \\
\hline Chemotherapy $^{1}$ & 49 & 10 & 3 & $36(17)$ & 72 \\
Chemotherapy $^{1}+$ BCG & 19 & 3 & 6 & $10(4)$ & 53 \\
Chemotherapy $^{1}+$ BCG + VO & 19 & 4 & 9 & $6(3)$ & 32 \\
\hline
\end{tabular}

${ }^{1}$ vincristine, cyclophosphamide, adriamycin/actinomycin D, DTIC

$\mathrm{VO}=$ sarcoma viral oncolysate prepared from allogeneic cell lines with PR8 influenza A virus [70]

Patients with metastatic sarcomas either received standard adriamycin-based chemotherapy or chemotherapy plus BCG scarifications. The third group of patients received in addition autologous (when available) or allogeneic sarcoma viral oncolysates prepared with the PR8 influenza A virus (which was shown to replicate in human sarcoma cells). In the third group of patients, BCG was scarified over the intra- or subcutaneous injection sites of the viral oncolysate vaccine administration. In this third group of patients progression of disease was halted and a remission rate better than in the first and second group of patients was induced [70].

\section{VIRAL ONCOLYSATE VACCINES}

\section{First trials}

Mice injected with virus-infected transplantable tumor lysates reject a following tumor cell challenge; postoncolytic immunity develops [67, 68]. The first clinical trial with PR8 influenza A virus was conducted at MD Anderson Hospital (Houston TX) by 
one of us (JGS) and showed its effectiveness in sarcomas and solid tumors [69]. The patients developed antibody- and cell mediated immune response against allogeneic and autologous (when available) tumor cells. In patients with metastatic disease chemo- and immunotherapy were sequentially used, immunotherapy being used when patients rebounced from myelosuppression. The chemo-immunotherapy induced remissions of long duration and prevented late relapses [70-74]. Here we re-produce some of the original tabulated results (Tables I, II and III). It is noticeable that relapses happened in all three groups of patients treated with sarcomas, but the least frequent recurrences occurred in the group of patients receiving chemotherapy with BCG and VO. Patients with stage IV metastatic melanoma receiving chemo-immunotherapy in a therapeutic setting had the longest survival compared to patients receiving chemotherapy with or without nonspecific immunostimulation (BCG). These results are among the first documentations of the fact that pulsed chemotherapy combined with immunotherapy can be additive against a targeted tumor.

Table II

Time intervals (in months) for patients with Stage IV melanoma receiving chemo-immunotherapy

\begin{tabular}{lc}
\hline Treatment & Length of survival (mo) \\
\hline Chemotherapy $^{1}$ & 5.1 \\
Chemotherapy $^{1}+$ BCG & 6.25 \\
Chemotherapy $^{1}+$ BCG + VO & 12.8 \\
\hline
\end{tabular}

${ }^{1}$ DTIC (dacarbazine), vincristine or nitrosourea, actinomycin D

$\mathrm{VO}=$ viral oncolysate of allogeneic melanoma vaccine prepared from well-characterized

cell lines with PR8 influenza A virus, harvested, disintegrated and UV irradiated [71]

Metastatic malignant melanoma was treated in the early 1970s with nitrosourea and dacarbazin. Administration of BCG in addition to chemotherapy did not significantly prolong survival (mean 5 vs. 6 months). Patients also receiving autologous or allogeneic PR8 influenza A viral oncolysate vaccine (melanoma cells grown in culture and lysed by the virus) experienced significant prolongation of survival: mean 12 months. This often occurred coincidentally with partial remissions, minor responses and stabilizations of disease and only seldom consequentially to complete remissions. In this report treatment schedules for adjuvant therapy and better "no evidence of disease" survival in stages II and III disease are also listed favoring the administration of viral oncolysates over controls. Without prospective randomization of patients, only a favorable trend for better responses and longer survivals for patients receiving viral oncolysate vaccine could be reported [71].

W. Cassel (Emory University Atlanta GA) used the Lederle's strain 73T (which he adapted to mouse ascites tumor) of Newcastle disease virus (NDV) to prepare viral oncolysate melanoma vaccines. Patients with stage II metastatic melanoma, rendered clinically disease free by surgical resection, received autologous or allogeneic vaccine in an adjuvant setting to prevent late recurrence of the disease. No adjuvants were used for 
his vaccine and the patients received no chemotherapy. Surgical samples from central nervous system (CNS) recurrences showed extensive inflammatory infiltration of the tumor; such infiltration was absent in all brain metastases from non-vaccinated patients. The 10 year follow-up of 83 treated patients showed and unprecedented $61 \%$ survival rate compared to $33 \%$ survival in historical controls $[75,76]$. These excellent results are grossly overlooked and seldom cited.

Table III

Chemo-immunotherapy for Stage III melanoma

\begin{tabular}{lcccc}
\hline Treatment & Patients & NED 2nd year & $\begin{array}{c}\text { Relapses with } \\
\text { melanoma 1978-80 }\end{array}$ & NED 1981 (5th year) \\
\hline Chemotherapy+BCG & 34 & 17 & 7 & $10(6 \mathrm{~m}, 4 \mathrm{f}) 29 \%$ \\
Chemotherapy+BCG+VO & 30 & 13 & $0^{*}$ & $11(5 \mathrm{~m}, 6 \mathrm{f}) 36 \%$ \\
\hline
\end{tabular}

${ }^{1}$ DTIC (dacarbazine), vincristine or nitrosourea, actinomycin D

$\mathrm{VO}=$ viral oncolysate of allogeneic melanoma vaccine prepared from well-characterized cell lines with PR8

influenza A virus, harvested, disintegrated and UV irradiated (72)

* 2 deaths with prostate and colon cancer (no melanoma)

In a group of patients with stage III malignant melanoma (massive lymph node metastases surgically removed) chemotherapy with BCG or chemotherapy, BCG and PR8 viral oncolysate autologous or allogeneic melanoma vaccines were given. The viral oncolysate vaccinations were administered in between courses of chemotherapy when blood counts were returning toward normal. In the group of patients receiving chemotherapy and BCG relapses continued up to the 5th year; in the group of patients receiving chemotherapy, BCG and melanoma viral oncolysates relapse rate was reduced and no relapses occurred after the 3rd year [72]. Interpretation: patients destined to relapse due to clinically undetectable but major metastases relapsed equally in both groups; patients with micrometastases were protected from relapse by VO vaccine.

In vitro studies documented increased lymphocyte-mediated cytotoxicity toward autologous (when available) and allogeneic melanoma cells in long-term survivors of the disease [for review see 113].

\section{Current trials}

A Phase II clinical trial of an allogeneic melanoma oncolysate made with vaccinia virus suggested a longer DFI and overall survival (OS) of vaccinated patients with Stage III melanoma compared to the control group receiving a vaccine containing the vaccinia virus only. A multicenter randomized Phase III trial, however, found no significant difference in DFI and OS between the OV vaccinated group of patients and patients receiving the virus only. The subset of men having 1-5 nodes and aged 44-57 years, 
however, enjoyed $21 \%$ higher 5 years survival than the control group of same gender and age $[77,78]$.

The autologous renal cell carcinoma viral oncolysate vaccine prepared with Cassel's strain of NDV was extensively tried and found successful to prevent recurrence in a clinical trial in Germany. As adjuvant subcutaneous low dose IL-2 and IFN $\alpha$ were applied. Over 200 patients were included with locally advanced renal cell carcinoma. An interim evaluation of the patients who received the vaccine for at least 22 months found that the relapse rate was $18 \%$, lower than in the historical control group [79].

Based on extensive preclinical studies a virally modified vaccine made with the non-lytic Ulster strain of NDV was used by Schirrmacher and his group in Germany for active tumor-specific immunotherapy of a range of different tumors in an adjuvant setting. Tumor cells prepared from surgical samples were used directly, without culturing. Cryopreserved cell suspensions were thawed immediately before use, lethally irradiated and infected with NDV-Ulster for $1 \mathrm{~h}$ and injected intradermally. Patients immunized with virus-modified, irradiated autologous tumor cells developed delayed type hypersensitivity reaction against non-modified tumor cell antigen. The efficiency of the vaccine depended on the viability of the injected tumor cells. VO vaccine extended survival of patients with mammary carcinoma and with ovarian carcinoma [80, 81]. Stage II melanoma patients received the NDV-Ulster VO vaccines and experienced extended overall survival depending on the quality (number, viability, etc.) of the cells in the applied vaccine. Out of 23 patients vaccinated with the NDV modified autologous colon cancer vaccine 13 developed DTH reaction to unmodified tumor cell antigens; after 18 mo follow-up $61 \%$ recurred vs. $87 \%$ in patients treated only surgically [82]. Tumor cells were disseminated to the bone marrow of patients with mammary (4), stomach (7), pancreas carcinomas (2) and glioblastomas (2). The bone marrow of $90 \%$ of these patients became tumor cell free after active tumor-specific vaccination [79].

At MD Anderson Cancer Center clinical trials elegantly demonstrated the efficacy of PR8 oncolysate vaccines to treat vulvar squamous cell carcinoma and applied intraperitoneally to treat ovarian carcinoma with peritoneal carcinomatosis. Application of the vaccine is followed by IL-2 and TNF $\beta$ (lymphotoxin) secretion in the ascites or in vitro by the lymphoid cells. $\mathrm{CD}^{+} \mathrm{T}$ cells respond with proliferation to NDVO and tumor cell lysate proving that the vaccine raises $\mathrm{CD}^{+} \mathrm{CD}^{+} \mathrm{T}$ cell immune response against specific tumor antigens [83-85].

At St. Joseph's Hospital Cancer Institute patients suffering from malignant melanoma with high risk of recurrence are treated with autologous (if available) or allogeneic NDVO in an adjuvant setting. NDVO is found to be an efficient and safe vaccine. No serious side effects are observed and no infectious virus is secreted following application of the vaccine. Since the oncolytic potential of various NDV strains is highly variable, Cassel's $73 \mathrm{~T}$ strain was used in these clinical trials.

The clinical data of vaccinated patients support a beneficial effect of the vaccine for Stage II and III patients who enjoy extended disease free intervals and overall survival. Relapsed patients likely to have had multiple relapses, higher numbers of positive lymph nodes, thicker and more invasive primary tumors (average $5.5 \mathrm{~mm}$ vs. 2.3 for patients with no evidence of disease) in their history. 
The vaccine gave little benefit to patients with Stage IV disease. Out of 5 patients 2 had metastases in the brain, 1 in bone and liver and 3 in the lung before starting the vaccination.

\section{DISCUSSION}

\section{Postoncolytic immunity}

The mechanism of the postoncolytic immunity following application of NDVO is not clearly understood. The adjuvant effect of the virus is well demonstrated. Inoculation of PBMC with NDV enhances their cytotoxicity against tumor cells in vitro. IFN $\alpha$ and TNF production is induced in infected PBMC [86]. Schirrmacher's group elegantly demonstrated that mouse lymphoma cells infected with the non-lytic Ulster strain generated tumor-specific CTL which effect was inhibited with anti-IFN sera showing that IFN was responsible for the adjuvant effect [87]. NDV-infected or NDV HN transfected mouse fibroblasts (non-professional APC!) pulsed with antigenic peptides generate six times more efficiently CTL than unmodified fibroblasts [88]. In mice NDV induces MHC class I gene expression through the IRF1 and $\mathrm{KBF} 1 / \mathrm{NF} \mathrm{KB}$ cooperative action, by a mechanism partly different from IFN $\gamma$ [89]. Some viruses generate virus-specific $\mathrm{CD}^{+}$ CTL in CD4 depleted mice or in animals homozygous (-/-) in the disruption of class II major histocompatibility complex glycoprotein bypassing the need of $\mathrm{CD}^{+}$cells [90]. Does NDV have direct $\mathrm{CD}^{+}$CTL activating capabilities? The NDV induced NO synthesis is also activated through the NFkB pathways [91]. NDV is a potent inducer of heat shock proteins (HSP), a family of stress-induced proteins [92]. HSP are recently found to be efficient presenters of tumor-specific antigenic peptides to T-cells and are being in clinical trial as vaccines [reviewed in 93, 94].

The co-presentation of NDV and tumor antigens to naive or committed T cells is also subject of speculation. Is it presented in the MHC pocket as $i$. a virus-tumor antigen fusion peptide or $i$. two TCRs of the same T-cell with two different specificity recognize the side-by-side presented viral and tumor antigenic peptides on the APC? Our preliminary data suggest that iii. one or more virus proteins might act as superantigens linked to TCR and MHC at the same time. Do they serve the role of an accessory molecule, making the cell-cell connection stable and result in immunity instead of tolerance? Or could some NDV gp antigens mimic those of melanoma cells?

While NDV strains may widely differ in their oncolytic activities, Cassel's NDV $73 \mathrm{~T}$ behaves as an antineoplastic agent; $73 \mathrm{~T}$ preferentially multiplies and lyses tumor cells while normal cells such as fibroblasts are spared. Normal and fully transformed lymphoid cells bear the same number of receptors for NDV, the virus, however, preferentially causes lytic infection in lymphoma cells compared to lymphoblastoid cell lines (immortalized, not fully transformed) or PBL [95, 96]. Human neuroblastoma and fibrosarcoma xenografts transplanted to athymic nude mice regress completely after intratumoral injection of this virus [97]. 


\section{Critical comments}

What justifies the use of NDVO instead of other types of melanoma vaccines? Cytokine transfected or transduced tumor cells as vaccines are promising. However, at least in mouse experiments the results are controversial, as none of the IL-2, -4, -7, IFN $\gamma$ or TNF or their combination was found to be superior to irradiated tumor cells admixed with Corynebacterium parvum to protect mice against live mouse plasmacytoma cell challenge [98]. It is still uncertain, what are the antigens relevant to develop protective anti-tumor immunity; are the antigens represented in a vaccine present in the particular patient's tumor as well? If the loss of a tumor-specific antigen does not impair the functions of the tumor cell it can be down-regulated rendering the tumor cell resistant toward the immune response generated by a monospecific vaccine. The use of vaccines specific to a single tumor specific antigen seems to be limited to virus induced tumors (E6 or E7 of human papillomavirus in cervical carcinoma or LMP in EBV associated lymphomas of the immunosuppressed patients) and malignancies where the tumor antigen generated by mutation represents a new entity (such as the fusion protein ABL-BCR generated by chromosomal translocation) and is presented in every tumor of that kind [99, $100]$.

The role of adjuvants cannot be accentuated enough. The HER2 oncoprotein itself was ineffective to protect mice against HER2-transfected fibrosarcoma while animals immunized with the same protein complexed with a hydrophobized polysaccharide nanoparticle developed humoral as well as CD8+ cytotoxic T-cell mediated protective immunity. Combination of vaccines with interferons and other cytokines as adjuvants can efficiently boost the immune response and make the vaccine more effective $[4,101,102]$.

In spite of good in vitro signs tumor cells escape the immune surveillance and relapses occur. The known reasons outnumber the presently available resolutions.

Melanoma cells often express immunosuppressive biologically active substances. In the presence of IL-10 it is a Th2 type immunity what develops with preferentially antibody production instead of tumor specific cytotoxic immunity. IL-10 decreases the production of IFN $\alpha$ [103]. CD40, CD86 and HLA-DR expression is reduced in IL-10 treated macrophages; such APC fail to activate T-cells [104]. MHC antigens are often underexpressed on human tumor cells, however, interferons $\gamma$, and (less efficiently) $\alpha$ and $\beta$ increase MHC expression [105]. Immune lymphocytes eliminate invading tumor cells by the perforine-granzyme $\mathrm{B}$ pathway or by expressing the ligands FasL and TNF inducing programmed death [106]. Coupling of these ligands to their receptors on the Fas/APO- $1^{+}$tumor cells induces pre-programmed molecular events leading to DNA fragmentation, cytoplasm membrane blebbing, cell shrinkage and ultimately cell death followed by phagocytosis practiced by the surrounding cells. Melanoma cells produce FasL and counterattack $\mathrm{Fas}^{+}$lymphocytes and thus protect themselves from being killed [107-111]. A recent report demonstrates, however, that $\mathrm{CD}^{+}$and $\mathrm{CD}^{+}$lymphocyte populations kill melanoma cells with the perforin-granzyme $\mathrm{B}$ mechanism and overcome the FasL ${ }^{\mathrm{MC}} \rightarrow$ FasR $^{\mathrm{Ly}}$ counterattack [112]. Successful immunotherapeutic modalities have to address these problems. In our next generation NDVO we plan to include IFN $\alpha$ and/or 
IL-2 as adjuvants to overcome decreased MHC expression and induce activation and proliferation of cytotoxic T-cells generated by the vaccine.

\section{REFERENCES}

1. Ferrone,S., Marincola,F.M.: Loss of HLA class I antigens by melanoma cells: molecular mechanism, functional significance and clinical relevance. Immunol Today 16, 487 (1995).

2. Kiessling,R., Kono,K., Petersson,M., Wasserman,K.: Immunosuppression in human tumor-host interaction: role of cytokines and alterations in signal-transducing molecules. Springer Semin Immunopathol 18, 227 (1996).

3. Mitchell,M.S., Kan-Mitchell,J., Kempf,R.A., Harel,W., Shau,H., Lind,S.: Active specific immunotherapy for melanoma: Phase I trial of allogeneic lysates and a novel adjuvant. Cancer Res 48, 5883 (1988).

4. Pomer,S., Thiele,R., Stahler,G., Drehmer,I., Lohrke,H., Schirrmacher,V.: Tumor vaccination in renal cell carcinoma with and without interleukin-2 (IL-2) as adjuvant. A clinical contribution to the development of effective active specific immunization. Urologe A 34, 215 (1995).

5. Bronte,V., Tsung,K., Rao,J.B., Chen,P.W., Wang,M., Rosenberg,S.A., Restifo,N.P.: IL-2 enhances the function of recombinant poxvirus-based vaccines in the treatment of established pulmonary metastases. J Immunol 154, 5282 (1995).

6. Storkus,W.J., Zeh,H.J., Maeurer,M.J., Salter,R.D., Lotze,M.T.: Identification of human melanoma peptides recognized by Class I restricted tumor infiltrating lymphocytes. J Immunol 151, 3719 (1993).

7. Bernhardt,H., Jager,E., Maeurer,M.J., Meyer zum Buschenfelds,K.H., Knuth,A.: Tumor associated antigens in human renal cell carcinoma: MHC restricted recognition by cytotoxic $\mathrm{T}$ lymphocytes. Tissue Antigens 48, 22 (1996).

8. Robbins,P.F., Kawakami,Y.: Human tumor antigens recognized by T cells. Curr Opinion in Immunol 8, 628 (1996).

9. Lupetti,R., Pisarra,P., Verrecchia,A., Farina,C., Nicolini,G., Anichini,A., Bordignon,C., Sensi,M., Parmiani,G., Traversari,C.: Translation of a retained intron in tyrosinase-related-protein (TRP) 2 mRNA generates a new cytotoxic $\mathrm{T}$ lymphocyte (CTL)-defined and shared human melanoma antigen not expressed in normal cells of the melanoma lineage. J Exp Med 188, 1005 (1998).

10. Vierboom,M.P., Nijman,H.W., Offringa,R., van der Voort,E.I., van Hall,T., van der Broek,L., Fleuren,G.J., Kenemans,P., Kast,W.M., Melief,C.J.: Tumor eradication by wild-type p53-specific cytotoxic T lymphocytes. J Exp Med 186, 695 (1997).

11. Van Pel,A., van der Bruggen,P., Coulie,P.G., Brichard,V.G., Lethe,B., van den Eynde,B., Uyttenhove,C., Renauld,J.C., Boon,T.: Genes coding for tumor antigens recognized by cytolytic T lymphocytes. Immunology Rev 145, 229 (1995).

12. Rosenberg,S.A., Kawakami,Y., Robbins,P.F., Wang,R.F.: Identification of genes encoding cancer antigens: implications for cancer immunotherapy. Adv Cancer Res 70, 145 (1996).

13. Matsui,K., Boniface,J.J., Reay,P.A., Schild,H., Fazekas de St. Groth,B., Davis,M.M.: Low affinity interaction of peptide-MHC complexes with T-cell receptors. Science 254, 1788 (1991).

14. Couderc,B., Zitvogel,L., Douin-Echinard,V., Gjennane,L., Tahara,H., Favre,G., Lotze,M.T., Robbins,P.D.: Enhancement of antitumor immunity by expression of CD70 (CD27 ligand) or CD154 (CD40 ligand) costimulatory molecules in tumor cells. Cancer Gene Ther 5, 163 (1998).

15. Ohmori,T., Okada,K., Arita,N., Watanabe,Y., Miyazaki,T., Taberi,R.: Characteristics of MHC antigen expression and tumor-infiltrating mononuclear cells in renal cell adenomas and carcinomas. Histol Histopathol 10, 789 (1995). 
16. Cordon-Cardo,C., Fuks,Z., Drobnjak,M., Moreno,C., Eisenbach,L., Feldman,M.: Expression of HLAA,B,C antigens on primary and metastatic tumor cell populations of human carcinomas. Cancer Res 51, 6372 (1991).

17. Marincola,F.M., Shamamian,P., Alexander,R.B., Gnarra,J.R., Turetskaya,R.L., Nedospasov,S.A., Simonis,T.B., Taubenberger,J.K., Yannelli,J., Mixon,A., Restifo,N.P., Herlyn,M., Rosenberg,S.A.: Loss of HLA haplotype and B locus down-regulation in melanoma cell lines. J Immunol 153, 1225 (1994).

18. Natali,P.G., Nicotra,M.R., Bigotti,A., Venturo,I., Marcenaro,L., Giacomini,P., Russo,C.: Selective changes in expression of HLA Class I polymorphic determinants in human solid tumors. Proc Natl Acad Sci USA 86, 6719 (1989).

19. Sinkovics,J., Horvath,J., Horak,A.: Lymphocytes cytotoxic to human tumor cells. In Rao,R.S., Deo,M.G., Sanghvi,L.D., Mittra,I. (eds): Proceedings of the XVI International Cancer Congress. Bologna, Italy, 1994. pp. 93-102

20. Luboldt,H.J., Kubens,B.S., Rubben,H., Grosse-Wilde,H.: Selective loss of human leukocyte antigen class I allele expression in advanced renal cell carcinoma. Cancer Res 56, 826 (1996).

21. Restifo,N.R., Marincola,F.M., Kawakami,Y., Taubenberger,J., Yannelli,J.R., Rosenberg,S.A.: Loss of functional beta 2-microglobulin in metastatic melanomas from five patients receiving immunotherapy. JNCI 88, 100 (1996).

22. Maeurer,M.J., Gollin,S.M., Storkus,W.J., Swaney,W., Karbach,J., Martin,D., Castelli,C., Salter,R., Knuth,A., Lotze,M.T.: Tumor escape from immune recognition: loss of HLA-A2 melanoma cell surface expression is associated with a complex rearrangement of the short arm of chromosome 6. Clin Cancer Res. 2, 641 (1996).

23. Everson,M.P., Lemak,D.G., McDuffie,D.S., Koopman,W.J., McGhee,J.R., Begley,W.W.: Dendritic cells from Peyer's patch and spleen induce different T helper cell responses. J. Interferon Cytokine Res 18, 103 (1998).

24. Michell,M.S., Harel,W., Kan-Mitchell,J., LeMay,L.G., Goedegebuure,P., Hang,X.Q., Hoffman,F., Groshen,S.: Active specific immunotherapy of melanoma with allogeneic cell lysates. Rational, results, and possible mechanisms of action. Ann N Y Acad Sci 690, 153 (1993).

25. Mitchell,M.S., Jakowitz,J., Harel,W., Dean,G., Stevenson,L., Boswell,W.D., Groshen,S.: Increased effectiveness of interferon alpha-2B following active specific immunotherapy for melanoma. J Clin Oncol 12, 402 (1994)

26. Mitchell,M.S., Liggett,P.E., Kan-Mitcell,J., Murphree,A.L., Dean,G., Spears,L., Walonker,F.: Sustained regression of a primary choroidal melanoma under the influence of a therapeutic melanoma vaccine. J Clin Oncol 12, 396 (1994).

27. von Eschen,K.B., Mitchell,M.S.: Phase III trial of melacine melanoma therracine versus combination chemotherapy in the treatment of stage IV melanoma. Oral abstracts of the 4th World Conference on Melanoma. Melanoma Res 7, S51 (1997).

28. Sinkovics,J.G., Plager,C., McMurray,M.J.: Chemoimmunotherapy: basic principles and clinical examples, Adv Med Oncol, Research and Education (M. Moore, ed.) Oxford, New York: Pergamon Press 6, 121 (1979).

29. Morton,D.L., Foshag,L.J., Hoon,D.S.B., Nizze,J.A., Wanek,L.A., Chang,C., Davtyan,D.G., Gupta,R.K., Elashoff,R., Irie,R.F.: Prolongation of survival in metastatic melanoma after active specific immunotherapy with a new polyvalent melanoma vaccine. Ann Surg 216, 463 (1992).

30. Berd,D., Maguire,H.C., Mastrangelo,M.J.: Treatment of human melanoma with a hapten-modified autologous vaccine. Ann NY Acad Sci 690, 147 (1993).

31. Berd,D., Maguire,H.C., Schuchter,L.M., Hamilton,R., Hauck,W.W., Sato,T., Mastrangelo,M.J.: Autologus hapten-modified melanoma vaccine as postsurgical adjuvant treatment after resection of nodal metastases. $\mathrm{J}$ Clin Oncol 15, 2359 (1997). 
32. Sensi,M., Farina,C., Maccalli,C., Anichini,A., Berd,D., Parmiani,G.: Intralesional selection of $\mathrm{T}$ cell clonotypes in the immune response to melanoma antigens occurring during vaccination. J Immunother 21, 198 (1998).

33. Kageshita,T., Hirai,S., Ono,T., Ferrone,S.: Human high molecular weight-melanoma associated antigen mimicry by mouse anti-idiotypic MAb MK2-23. Immunohistochemical analysis of the reactivity of antiidiotypic MAb with surgically removed melanoma lesions. Int J Cancer 6, 334 (1995).

34. Sharma,S., Miller,P.W., Stolina,M., Zhu,L., Huang,M., Paul,R.W., Dubinett,S.M.: Multicomponent gene therapy vaccines for lung cancer: effective eradication of established murine tumors in vivo with interleukin-7/herpes simplex thymidine kinase-transduced autologous tumor and ex vivo activated dendritic cells. Gene Ther 4, 1361 (1997).

35. Jaffe,E.M., Dranoff,G., Cohen,L.K.L., Hauda,K.M., Clif,S., Marshall,F.F., Mulligan,R.C., Pardoll,D.M.: High efficiency gene transfer into primary human tumor explants without cell selection. Cancer Res $\mathbf{5 3}$, 2221 (1993).

36. Schweighoffer,T., Berger,M., Buschle,M., Schmidt,W., Birnstiel,M.L.: Adenovirus-enhanced receptormediated transferrinfection for the generation of tumor vaccines. Cytokines Mol Ther 2, 185 (1996).

37. Abdel-Wahab,Z., Weltz,C., Hester,D., Pickett,N., Vervaert,C., Barber,J.R., Jolly,D, Seigler,H.F.: A Phase I clinical trial of immunotherapy with interferon-gamma gene-modified autologous melanoma cells: monitoring the humoral immune response. Cancer 80, 401 (1997).

38. Elder,E.M., Lotze,M.T., Whiteside,T.L.: Successful culture and selection of cytokine gene-modified human dermal fibroblasts for the biological therapy of patients with cancer. Hum Gene Ther 7, 479 (1996).

39. McArthur,J.G., Mulligan,R.C.: Induction of protective anti-tumor immunity by gene-modified dendritic cells. J Immunother 21, 44 (1998).

40. Tuting,T., DeLeo,A.B., Lotze,M.T., Storkus,W.J.: Genetically modified bone marrow-derived dendritic cells expressing tumor-associated viral or "self" antigens induce antitumor immunity in vivo. Eur J Immunol 27, 2702 (1997).

41. Miller,K., Abeles,G., Oratz,R., Zeleniuch-Jacquotte,A., Cui,J., Roses,D.F., Harris,M.N., Bystrin,J-C.: Improved survival of patients with melanoma with an antibody response to immunization to a polyvalent melanoma vaccine. Cancer 75, 495 (1995).

42. Bystryn,J-C., Henn,M., Li,J., Shroba,S.: Identification of immunogenic human melanoma antigens in a polyvalent melanoma vaccine. Cancer Res 52, 5948 (1992).

43. Chu,J.W., Sharom,F.J: Gangliosides inhibit T-lymphocyte proliferation by preventing the interaction of interleukin-2 with its cell surface receptors. Immunol 79, 10 (1993).

44. Helling,F., Zhang,S., Shang,A., Adluri,S., Calves,M., Koganty,R., Longenecker,B.M., Yao,T.J., Oettgen,H.F., Livingston,P.O.: GM2-KLH conjugate vaccine: increased immunogenicity in melanoma patients after administration with immunological adjuvant QS-21. Cancer Res 55, 2785 (1995).

45. Ritter,G., Ritter-Boosfeld,E., Adluri,R., Calves,M., Ren,S., Yu,R.R., Oettgen,H.F., Old,L.J., Livingston,P.O.: Analysis of the antibody response to immunization with purified O-acetyl GD3 gangliozides in patients with malignant melanoma. Int J Cancer 62, 668 (1995).

46. Livingston,P.O., Zhang,S., Adluri,S., Yao,T.J., Graeber,L., Ragupathi,G., Helling,F., Fleisher,M.: Tumor cell reactivity mediated by IgM antibodies in sera from melanoma patients vaccinated with GM2 ganglioside covalently linked to KLH is increased by $\operatorname{IgG}$ antibodies. Cancer Immunol Immunother $\mathbf{4 3}$, 324 (1997).

47. Rosenberg,S.A., Yang,J.C., Schwartzentruber,D.J., Hwu,P., Marincola,F.M., Topalian,S.L., Restifo,N.P., Dudley,M.E., Schwarz,S.L., Spiess,P.J., Wunderlich,J.R., Parkhurst,M.R., Kawakami,Y., Seipp,C.A., Einhorn,J.H., White,D.E.: Immunologic and therapeutic evaluation of a synthetic peptide vaccine for the treatment of patients with metastatic melanoma. Nat Med 4, 321 (1998).

48. Gong,J., Chen,D., Kishiwaba,M., Kufe,D.: Induction of antitumor activity by immunization with fusions of dendritic and carcinoma cells. Nature Medicine 3, 558 (1997). 
49. Nair,S.K., Snyder,D., Rouse,B.T., Gilboa,E.: Regression of tumors in mice vaccinated with professional antigen-presenting cells pulsed with tumor extracts. Int J Cancer 70, 706 (1997).

50. Nestle,O.F., Alijagic,S., Gilliet,M., Sun,Y., Grabbe,S., Dummer,R., Burg,G., Schadendorf,D.: Vaccination of melanoma patients with peptide- or tumor lysate-pulsed dendritic cells. Nature Medicine 4, 328 (1998).

51. Earl,P.L., Moss,B., Morrison,R.P., Wehrly,J., Nishio,J., Chesebro,B.: T-lymphocyte priming and protection against Friend leukemia by vaccina-retrovirus env gene recombinant. Science 234, 728 (1986).

52. Lathe,R., Kieny,M.P., Gerlinger,P., Clertant,P., Guizan,I., Cuzin,F., Chambon,P.: Tumour prevention and rejection with recombinant vaccinia. Nature (London) 326, 878 (1987).

53. Gu,S., Huang,T., Miao, Y., Ruan,L., Zhao,Y., Han,C., Xiao,Y., Zhu,J., Wolf,H.: A preliminary study on the Immunogenicity in rabbits and in human volunteers of a recombinant vaccinia virus expressing EpsteinBarr virus membrane antigen. Chin Med Sci J 6, 241 (1991).

54. Hu,Sh-L., Plowman,G.D., Sridhar,P., Stevenson,U.S., Brown,J.P., Estin,C.D.: Characterization of a recombinant vaccinia virus expressing human melanoma-associated antigen p97. J Virol 62, 176 (1988).

55. Mandl,S., Sigal,L.J., Rock,K.L., Andino,R.: Poliovirus vaccine vectors elicit antigen-specific cytotoxic T cells and protect against lethal challenge with malignant melanoma cells expressing a model antigen. PNAS 95, 8216 (1998).

56. Roth,J., Dittmer,D., Rea,D., Tartaglia,J., Paoletti,E., Levine,A.J.: p53 as a target for cancer vaccines: recombinant canarypox virus vectors expressing p53 protect mice against lethal tumor cell challenge. PNAS 93, 4781 (1996).

57. Fong,I., Ruegg,C.L., Brockstedt,D., Engelman,E.G., Laus,R.: Induction of tissue-specific autoimmune prostatitis with prostatic acid phosphatase immunization: implications for immunotherapy of prostate cancer. J Immunol 159, 3113 (1997).

58. Boursnell,M.E., Rutherford,E., Hickling,J.K., Rollinson,E.A., Munro,A.J., Rolley,N., McLean,C.S., Borysiewicz,L.K., Vousden,K., Inglis,S.C.: Construction and characterization of a recombinant vaccinia virus expressing papillomavirus proteins for immunotherapy of cervical cancer. Vaccine 14, 1485 (1996).

59. Borysiewicz,L.K., Fiander,A., Nimoako,M., Wilkinson,G.W., Westmoreland,D., Evans,A.S., Adams,M., Stacey,S.N., Boursnell,M.E., Rutherford,E., Hickling,J.K., Inglish,S.C.: A recombinant vaccinia virus encoding human papillomavirus types 16 and 18, E6 and E7 proteins as immunotherapy for cervical cancer. Lancet 347, 1523 (1996).

60. Hariharan,K., Braslawsky,G., Barnett,R.S., Berquist,L.G., Huynh,T., Hanna,N., Black,A.: Tumor regression in mice following vaccination with human papillomavirus E7 recombinant protein in PROVAX. Int J Oncol 12, 1229 (1998).

61. Hodge,J.W., Schlom,J., Donohue,S.J., Tomaszewski,J.E., Wheeler,C.W., Levine,B.S., Gritz,L., Panicali,D., Kantor,J.A.: A recombinant vaccinia virus expressing human prostate-specific antigen (PSA): safety and immunogenicity in a non-human primate. Int J Cancer 63, 231 (1995).

62. Irvin,K.R., Chamberlain,R.S., Shulman,E.P., Surman,D.R., Rosenberg,S.A., Restifo,N.P.: Enhancing efficacy of recombinant anticancer vaccines with prime/boost regiment that use two different vectors. J Natl Cancer Inst 89, 1595 (1997).

63. Donnelly,J.J., Ulmer,J.B., Shiver,J.W., Liu,M.A.: DNA vaccines. Ann Review Immunol 15, 617 (1997)

64. Mahvi,D.M., Sheehy,M.J., Yang,N.S.: DNA cancer vaccines: a gene gun approach. Immunol Cell Biol 75 , 456 (1997).

65. Stopeck,A.T., Hersh,E., Akporiaye,E.T., Harris,D.T., Grogan,T., Unger,E., Warneke,J., Schluter,S.F., Stahl,S.: Phase I study of direct gene transfer of an allogeneic histocompatibility antigen, HLA-B7, in patients with metastatic melanoma. J Clin Oncol 15, 341 (1997).

66. Waddill,W., Wright,W., Unger,E., Stopeck,A.T., Akporiaye,E., Harris,D., Grogan,T., Schluter,S., Hersh,E., Stahl,S.: Human gene therapy for melanoma: CT guided interstitial injection. AJR Am J Roentgenol 169, 63 (1997).

67. Lindenmann,J., Klein,P.: Immunological aspects of viral oncolysis. Recent Results Cancer Res 9, 1 (1967).

68. Koprowski,H., Love,R., Koprowska,I.: Viruses and tumor growth. Tex Rep Biol Med 15, 111 (1957). 
69. Sinkovics,J.G., Thota,H., Kay,H.D., Loh,K.K., Williams,D.E., Howe,C.D., Schullenberger,C.C.: Intensification of immune reactions by immunotherapy. Attempts at measuring sarcoma-specific reactions in vitro. In: Crispen,R.G. (ed.): Neoplasm Immunity: Theory and Application. Evanston, University of Illinois Press, 1974. pp. 137-152

70. Sinkovics,JG, Plager,C, Romero,J.J.: Immunology and immunotherapy of patients with sarcomas. In Crispen,R. (ed.): 1977 Chicago Symposium: Immunotherapy of Solid Tumors. Franklin Institute Press, Philadelphia PA. 1977. pp. 211-219

71. Sinkovics,J.G., Plager,C., McMurray,M., Papadopoulos,N.E., Waldinger,R., Combs,S., Romero,J.J., Romsdahl,M.M.: Adjuvant chemo immunotherapy for malignant melanoma. In Crispen,R. (ed.): Neoplasm Immunity: Experimental and Clinical. Elsevier North Holland, New York, Amsterdam. 1980. pp. 481-519

72. Sinkovics,J.G., Papadopoulos,N.E., Plager,C.: Viral oncolysates for the immunotherapy of human tumors. In Yohn,D.S., Blakeslee,J.J. (eds): Proceedings of the 10th International Symposium for Comparative Research on Leukemia and Related Diseases. Elsevier BioMed, New York, Amsterdam. 1981. pp. 613-615

73. Sinkovics,J.G.: Immunotherapy with viral oncolysates for sarcoma. JAMA 237, 869 (1977).

74. Sinkovics,J.G.: Complete remissions lasting over three years in adult patients treated for metastatic sarcoma. In Crispen,R. (ed.): Tumor Progression. Elsevier, Amsterdam, New York. 1980. pp. 315-331

75. Cassel,W.A., Weidenheim,K.M., Campbell,W.G., Murray,D.R.: Malignant melanoma. Inflammatory mononuclear cell infiltrates in cerebral metastases during concurrent therapy with viral oncolysates. Cancer 57, 1302 (1986).

76. Cassel,W.A., Murray,D.R.: A ten-year follow-up on stage II malignant melanoma patients treated postsurgically with Newcastle disease virus oncolysate. Med Oncol Tumor Pharmacother 9, 169 (1993).

77. Wallack,M.K., Bash,J.A., Leftheriotis,E., Seigler,H., Bland,K., Wanebo,H., Balch,C., Bartolucci,A.A.: Positive relationship of clinical and serological responses to vaccinia melanoma oncolysates. Arch Surg 122, 1460 (1987).

78. Wallack,M.K., Sivanandham,M., Balch,C.M., Urist,M.M., Bland,K.I., Murray,D., Robinson,W.A., Flaherty,L., Richards,J.M., Bartolucci,A.A., Rosen,L.: Surgical adjuvant active specific immunotherapy for patients with Stage III melanoma: The final analysis of data from a Phase III, randomized, double-blind, multicenter vaccinia melanoma oncolysate trial. J Am Coll Surg 187, 69 (1998).

79. Kirchner,H.H., Anton,P., Atzpodien,J.: Adjuvant treatment of locally advanced renal cell cancer with autologous virus-modified tumor vaccines. World J Urol 13, 171 (1995).

80. Schirrmacher,V., Ahlert,T., Pröbstle,T., Steiner,H.-H., Herold-Mende,C., Gerhards,R., Hagmüller,E.: Immunization with virus-modified tumor cells. Sem Oncol 25, 677 (1998).

81. Möbus,V., Horn,S., Stöck,M, Schirrmacher,V.: Tumor cell vaccination for gynecological tumors. Hybridoma 12, 543 (1993).

82. Schlag,P., Manasterski,M., Gerneth,T., Hohenberger,P., Dueck,M., Herfarth,C., Liebrich,M., Schirrmacher,V.: Active specific immunotherapy with Newcastle-disease-virus-modified autologous tumor cells following resection of liver metastases in colorectal cancer. First evaluation of clinical response of a phase II-trial. Cancer Immunol. Immunother 35, 325 (1992).

83. Freedman,R.S., Kouttab,N.M., Bowen,J.M., Edwards,C.L., Katz,R.L.: Lymphokine activity in malignant effusions after intracavity viral oncolysate. Lymphokine Res 8, 115 (1989).

84. Ioannides,C.G., Freedman,R.S., Patenia,R., Bowen,J.M., Ward,N.E., O’Brian,C.A.: Immunological effects of tumor vaccines: III Influenza virus oncolysates inhibit the TPA induced activation of peripheral blood mononuclear cells. In Vivo 5, 1 (1991).

85. Ioannides, C.G., Freedman,S.R.: T cell responses to ovarian tumor vaccines: identification and significance for future immunotherapy. Intern Rev Immunol 7, 349 (1991).

86. Zorn,U., Dallmann,I., Grosse,J., Kirchner,H., Poliwoda,H., Atzpodien,J.: Induction of cytokines and cytotoxicity against tumor cells by Newcastle disease virus. Cancer Biother 9, 225 (1994). 
87. von Hoegen,P., Zawatzky,R., Schirrmacher,V.: Modification of tumor cells by a low dose of Newcastle disease virus. III. Potentiation of tumor-specific cytotoxic T-cell activity via induction of interferon alpha/beta. Cell Immunol 126, 80 (1990).

88. Ertel,C., Millar,N.S., Emmerson,P.T., Schirrmacher,V., von Hoegen,P.: Viral hemagglutinin augments peptide-specific T cell responses. Eur J Immunol 23, 2592 (1993).

89. Ten,R.M., Blank,V., Le Bail,O., Kourilsky,P., Israel,A.: Two factors IRF1 and KNF1/NF-kappa B, cooperate during induction of MHC class 1 gene expression by interferon alpha, beta or Newcastle disease virus. C.R. Acad Sci III 316, 496 (1993).

90. Hou,S., Mo,X.T., Hyland,L., Doherty,P.C.: Host response to Sendai virus in mice lacking class II major histocompatibility complex glycoproteins. J Virol 69, 1429 (1995).

91. Umansky,V., Shatrov,V.A., Lehmann,V., Schirrmacher,V.: Induction of NO synthesis in macrophages by Newcastle disease virus is associated with activation of nuclear factor-kappa B. Int Immunol 8, 491 (1996).

92. Collins,P.L., Hightower,L.E.: Newcastle disease virus stimulates the cellular accumulation of stress (heat shock) mRNAs and proteins. J Virol 44, 703 (1982).

93. Edgington,S.M.: Therapeutic applications of heat shock proteins. Biotechnology 13, 1442 (1995)

94. Pardoll,D.M.: Cancer vaccines. Nat Med 4(5 Suppl.), 525 (1998)

95. Reichard,K.W., Lorence,R.M., Cascino,C.J., Peeples,M.E., Walter,R.J., Fernando,M.B., Reyes,H.M., Greager,J.A.: Newcastle disease virus selectively kills human tumor cells. J Surg Res 52, 448 (1992).

96. Bar-Eli,N., Giloh,H., Schlesinger,M., Zakay-Rones,Z.: Preferential cytotoxic effect of Newcastle disease virus on lymphoma cells. J Cancer Res Clin Oncol 122, 409 (1996).

97. Lorence,R.M., Katubig,B.B., Reichard,K.W., Phuangsab,A., Sassetti,M.D., Walter,R.J., Peeples,M.E.: Complete regression of human fibrosarcoma xenografts after local Newcastle disease virus therapy. Cancer Res 54, 6017 (1994).

98. Hock,H., Dorsch,M., Kunzendorf,U., Berla,K., Qin,Zh., Diamantstein,T., Blankenstein,T.: Vaccination with tumor cells genetically engineered to produce different cytokines: Effectivity not superior to a classical adjuvant. Cancer Res 53, 714 (1993).

99. Gu,X.G., Schmitt,M., Hiasa,A., Nagata,Y., Ikeda,H., Sasaki,Y., Akiyoshi,K., Sunamoto,J., Nakamura,H., Kuribayashi,K., Shiku,H.: A novel hydrophobized polysaccharide/oncoprotein complex vaccine induces in vitro and in vivo cellular and humoral immune responses against HER2-expressing murine sarcomas. Cancer Res 58, 3385 (1998).

100. Hariharan,K., Braslawsky,G., Barnett,R.S., Berquist,L.G., Huynh,T., Hanna,N., Black,A.: Tumor regression in mice following vaccination with human papillomavirus E7 recombinant protein in PROVAX. Int J Oncol 12, 1229 (1998)

101. McLaughlin,J.P., Schlom,J., Kantor,J.A., Greiner,J.W.: Improved immunotherapy of a recombinant carcinoembryonic antigen vaccine when given in combination with interleukin-2. Cancer Res 56, 2361 (1996).

102. Kirchner,H.H., Anton,P., Atzpodien,J.: Adjuvant treatment of locally advanced renal cancer with autologous virus-modified tumor vaccine. World J Urol 13, 171 (1995).

103. Payvandi,F., Amrute,S., Fitzgerald-Bocarsaly,P.: Exogenous and endogenous IL-10 regulate IFN production by peripheral blood mononuclear cells in response to viral stimulation. J Immunol 160, 5861 (1998).

104. Mottonen,M., Isomaki,P., Saario,R., Toivanen,P., Punnonen,J., Lassila,O.: Interleukin-10 inhibits the capacity of synmovial macrophages to function as antigen-presenting cells. Br J Rheumat 37, 1207 (1998).

105. Schwartz,R., Momburg,F., Moldenhauer,G., Dorken,B., Schirrmacher,V.: Induction of HLA class-II antigen expression on human carcinoma cell lines by IFN-gamma. Int J Cancer 35, 245 (1985).

106. Lee,R.K., Spielman,J., Zhao,D.Y., Olsen,K.J., Podack,E.R.: Perforin, Fas ligand, and tumor necrosis factor are the major cytotoxic molecules used by lymphokine-activated killer cells. J Immunol 157, 1919 (1996).

107. O’Connell,J., O’Sullivan,G.C., Collins,K., Shanahan,F.: The Fas counterattack: Fas-mediated T cell killing by colon cancer cells expressing Fas ligand. J Exp Med 184, 1075 (1996). 
108. Hahne,M., Rimaldi,D., Schroter,M., Romero,P., Schreier,M., French,L.E., Schneider,P., Bornand,T., Fontana,A., Lienard,D., Carottini,J., Tachopp,J.: Melanoma cell expression of Fas(APO-1/CD95) ligand: implication for tumor immune escape. Science 274, 1363 (1996).

109. Strand,S., Hofmann,W.J., Hug,H., Muller,M., Otto,G., Strand,D., Mariani,S.M., Stremmel,W., Krammer,P.H., Galle,P.R.: Lymphocyte apoptosis induced by CD95 (APO-1/Fas) ligand-expressing tumor cells - A mechanism of immune evasion? Nature Med 2, 1361 (1996).

110. Niehans,G.A., Brunner,T., Frizelle,S.P., Liston,J.C., Salerno,C.T., Knapp,D.J., Green,D.R., Kratzke,R.A.: Human lung carcinomas express Fas ligand. Cancer Res., 57, 1007 (1997).

111. Sinkovics,J.G.: Malignant lymphoma arising from natural killer cells: report of the first case in 1970 and newer developments in the FasL $\rightarrow$ FasR system. Acta Microbiol Immunol Hung 44, 295 (1997)

112. Rivoltini,L., Radrizzani,M., Accornero,P., Squarcina,P., Chiodoni,C., Mazzocchi,A., Castelli,C., Tarsini,P., Viggiano,V., Belli,F., Colombo,M.P., Parmiani,G.: Human melanoma-reactive $\mathrm{CD}^{+}$and $\mathrm{CD}^{+} \mathrm{CTL}$ clones resist Fas ligand-induced apoptosis and use Fas/Fas ligand-independent mechanisms for tumor killing. J Immunol 161, 1220 (1998).

113. Sinkovics,J.G.: Viral oncolysates as human tumor vaccines. Intern Rev Immunol 7, 259 (1991) 